\title{
Automatic Billing System for Classical Electrical Energy Meters
}

\author{
Ali M. El-Rifaie, Imad M. Nejdawi, Zaher Al Barakeh
}

\begin{abstract}
Electricity billing in some countries around the world is still being done following a traditional manual technique that relies mainly on people readings. This paper describes a simple smart metering system that could be easily implemented, and added to any existing type of energy meters. The system provides automatic consumption reading and bill calculation as well as the possibility of remote controlling loads. The system will eliminate the human errors inherit in the manual system thus improving the meter reading accuracy. It also reduces the data collection costs and improves the operational efficiency of the electric utility. In addition to the automatic meter reading, a system for switching loads is described as part of the introduced structure. The implementation is carried out through a microcontroller and GSM module.
\end{abstract}

Index Terms - Arduino (microcontroller), Global System for Mobile (GSM), Short Message Service (SMS), Smart Energy Meter.

\section{INTRODUCTION}

The traditional electricity meter reading and collection requires the periodic visit of a utility employee to the premises of the consumer to note the reading. The electric distribution utility is typically the entity responsible for billing and charging the electric energy consumers for their electric use. Employees who would go door-to-door and take the readings for further processing at the office, typically do the consumer electricity meter reading. The employee handles a huge number of meter readings during a day and in order to complete the task of reading all electricity meters a number of employees are needed. This procedure takes time and is prone to human error. The procedure could also be interrupted due to weather conditions or if the consumer was not present during the reading visit, issuing the bill and hence collection would be postponed. The present system of electricity billing in many countries adopts the manual meter reading process. Manual reading and billing could result in loss of revenues. This loss could be a result of reading errors, consumption estimation errors or non-payment due to lack of readings. To mitigate these issues, several available techniques could be used. The first technique is periodical monthly-based manual energy consumption calculation and bill payments. This manual approach will not eliminate errors, as the human factor still exists. The second technique is using pre-paid energy meters [4] that requires the substitution of existing meters with prepaid ones. This type of meters does not suit all customer categories due to multiple reasons and may not be

Ali M. El-Rifaie, College of Engineering and Technology, American University of the Middle East, Kuwait

Imad M. Nejdawi, College of Engineering and Technology, American University of the Middle East, Kuwait

Zaher Al Barakeh, College of Engineering and Technology, American University of the Middle East, Kuwait acceptable to the utility customers. One more solution would be using smart meters and their applications in smart grids is well documented and very much in use in certain parts of the world [8]. With the development of communication and information technologies, smart meters are gaining a lot of attention due to their numerous advantages and features and hence are increasingly being used in different parts of the world. They are used to monitor consumption, control loads and application of time of use electricity tariffs. Despite the high cost of smart meters compared to the traditional electricity meters, their use would result in better consumption data collection, more timely control of the loads, whether for the utility or the consumer, and elimination of unnecessary labor hence increasing the revenues, however it is very expensive, complicated and requires more time for complete installation.

In order to solve these problems, a smart electrical energy metering system that is capable of calculating the monthly bill, determining when the customer should pay in addition to controlling different home loads via mobile signals, is implemented.

In this paper, a full design and implementation of a smart metering system $[3,5,7]$ that is capable of converting the classical metering system from manual to automatic, as well as reducing the human errors inherit in taking the reading and performing the consumption calculations is introduced.

\section{PRojeCt AND DEIGN OBJECTIVES}

The main objective in this work is to develop an easy to use smart metering system that could solve all of the manual electric meter reading problems. A list of performance requirements that would define this smart meter operation was developed.

First: Provide monthly payments by consumers, in such a way that no cash flow problems are faced by the utility and consumers owe no large amounts as well.

Second: this system should reduce the number of unneeded employees in the utility, as the smart electric energy meter will do the job of the employees for readings and calculations. Third: the system should offer consumers the option of controlling their loads even if they are out of home or the country through SMS messages.

\section{DESIGN OF SMART ELECTRICAL ENERGY METERING SYSTEM}

\section{A. Proposed System}

A microcontroller needs to be used in order to convert the system to an automatic system. A special code needs to be developed in order to calculate the consumption in $\mathrm{KWh}$ and the monthly bill. The monthly bill amount will be sent to the consumer by SMS messaging using GSM module that is 
attached to the microcontroller [2,6]. Certain option could be envisaged where the bill will be sent to both consumer and the utility when the amount of energy consumption reaches a preset value that the user defines. Moreover, this system has an additional feature, which allows the consumer to control the loads in his house by using control units that are responsible for switching tasks through SMS messages.

\section{B. Block Diagram of Smart Electrical Energy Metering System}

The block diagram shown in figure 1 shows the basic parts and function of the smart electrical energy metering system and how these parts are interconnected; also the diagram explains the process of the smart meter system in details.

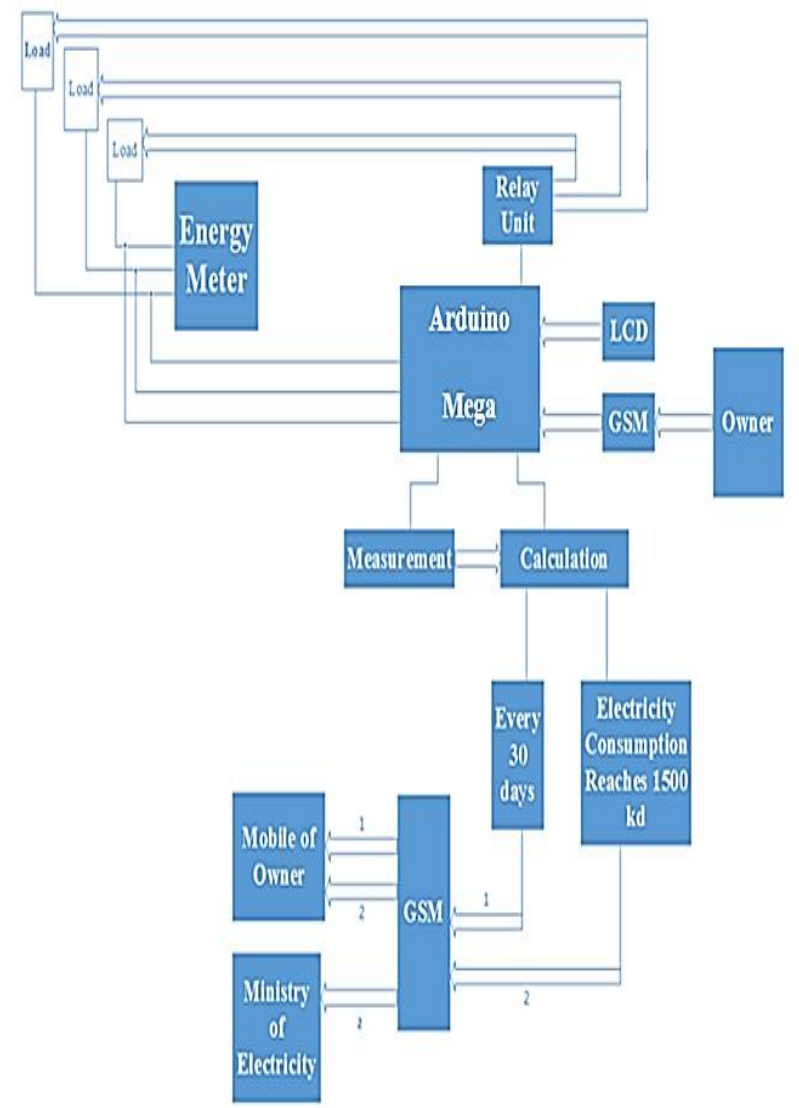

Fig. 1: Block diagram of smart electrical energy metering system

The components needed to implement the smart electrical energy metering system are:

a) Single-phase electronic meter.

b) Arduino mega 2560 .

c) GSM module SIM900.

d) $5 \mathrm{~V} 1$ channel relay module.

e) 16x4 LCD module blue with white backlight.

The following sections explain the functions of the different parts:

\section{SMART METERING SYSTEM DESIGN}

The smart electrical energy metering system is divided into four units as follows:

\section{A. Measurement Unit}

This unit consists of an electrical energy meter and Arduino mega. This unit is responsible for measuring the energy consumption in KWh. The Meter pulses are fed to Arduino mega $[2,6]$ that counts them using its built in interrupt function. The number of pulses that the energy meter gives is 1600 pulse per $\mathrm{kWh}$. The Arduino will use the received pulse from electronic energy meter in determining the amount of energy consumption.

\section{B. Calculation Unit}

This unit is responsible for calculating the monthly bill, as Arduino will convert the measured energy per month to money following eq. 1. In other words, the second unit to calculate the overall cost of electricity will use the amount of energy consumption that was found in the first unit.

$$
\text { cost }=K W h \times M
$$

Where the residential consumers' tariff assumed to be is M $\$ / \mathrm{KWh}$

In addition, the system can be programmed for different consumer categories with different tariffs if needed.

\section{Communication Unit}

The communication unit is mainly the GSM module [1,5], which is used for sending SMS messages to the consumer mobile. The purpose of this unit is to notify the consumer about his monthly bill; also, this unit is used to send warning messages to the consumer when consumption reaches a preset maximum. The power to the GSM is fed through the Arduino. This unit processes the amount of electricity consumption and its cost that is found in unit 1 and unit 2 and the GSM will send this data every 30 days to the consumer only. However, when the cost of energy consumption reaches a certain predetermined amount, the GSM will send it to both the utility and the consumer. The message will be sent to the consumer through his own mobile and the message will contain his current bill however, the GSM module will only send to utility the serial number of the consumer's energy meter.

A database in the utility should show all the data that is related to the consumer (through the meter's serial number) such as his name, civil ID, electricity consumption and the overall cost. There are different types of GSM but the one that was used here is SIM900A. In this unit, the communication between the Arduino and GSM is serial so for this reason the serial pins of Arduino, which are RX (receiver) and TX (transmitter), are used. RX of Arduino is connected with TX of GSM and TX of Arduino with RX of GSM and the GSM ground is connected to the ground of the Arduino.

The library that supports the communication between Arduino mega and GSM, <SoftwareSerial.h> was used; the pin RX10 and TX10 on Arduino is utilized to connect it to GSM. We used one of the most common libraries that supports the GSM SIM900A and specific functions were used for this unit. In addition, the connection between the cell tower and the GSM was tested, in case of no connection, there would be error in sending the message but if the connection is there, the SMS that contains the information of electricity consumption and its cost will be sent automatically to the mobile of owner that has been defined in the code. 


\section{Control Unit}

This unit contains a GSM module and a relay module [1]. It allows the consumer to control the critical loads in his house via SMS messages sent from his mobile. The consumer will have the option to control the loads in his house by only sending a message with on/off command and the chosen load will be switched on/off. The message can be sent from the user's mobile phone from wherever he/she is. The GSM module in this unit is used only to receive messages from the consumer, while the relay module will serve as a switch operator. The user will define a specific message for each load and the consumer can enter one of these messages.

The Arduino will receive a signal from the GSM and based on the command that GSM received from the consumer, the relay will switch the load on or off. For example, when the consumer sends ON1 to the GSM, the GSM will receive this signal and send it to Arduino and in turn, the Arduino will process it to allow the current to pass through the relay.

\section{DESIGN IMPLEMENTATION}

\section{A. Hardware Implementation}

Figure 2 shows the hardware implementation of the block diagram shown in figure 1. As shown in the diagram, the energy meter is connected to the Arduino for the measurement and calculation unit; the place where the pulse is generated is connected to interrupt pin to the Arduino. The GSM is connected to the Arduino through the transmitter and receiver pins for Sending and Receiving SMS's. Moreover, the relay is connected to each load, GSM and Arduino for the control unit.

\section{B. Software Implementation}

The Arduino IDE was used in order to write the code that implements the smart energy meter prototype. All the components should be connected to the Arduino and the communication between Arduino and each component is serial communication. That is the reason <software serial library> was included. To interface the Arduino with the GSM, the pertinent library that supports the GSM in order to make the communication between the Arduino and the GSM easier was included. The code checks the connection between the GSM and the cell tower; if there is service the consumer can start switching on the light and the meter will start reading the energy consumption. Then the equation, which will calculate the consumed KWh is defined and this calculation is based on the number of pulses that are generated from the meter as mentioned earlier. After that, the Arduino will use the amount of energy consumption and find the total bill using the applicable tariff. As soon as the billing period has ended (for example, one month), the GSM will send a message containing the bill to the consumer. On the other hand, when the consumption level goes beyond a preset value that is considered high by the consumer, the GSM will send a warning message to notify the consumer to reduce his usage or take any other appropriate action. Once the billing period ends and the required messages sent, the variables used in the calculations are reset and initialized to start a new billing period (except for the cumulative part for the calculation of the high consumption). When the cumulative consumption reaches a predetermined value, the GSM will send the serial number of consumer's energy meter to relevant entity in the utility.

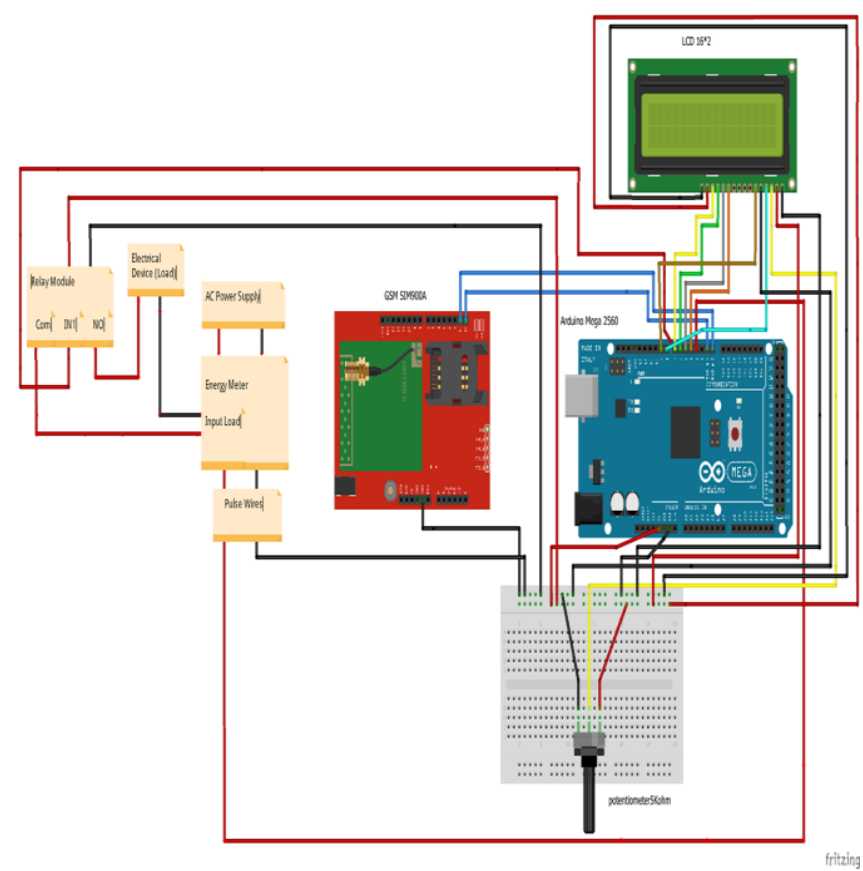

Fig. 2: Circuit diagram of smart electrical energy metering system

\section{Mathematical Equations}

The mathematical calculations used in implementing the smart electrical energy metering system are the following:

a) Pulse:

In the electronic energy meter, every 1600 pulse means that $1 \mathrm{KWh}$ was consumed and will be transmitted as a signal to the Arduino.

b) Elapsed KWh:

We define pulse Count to count the number of pulses when the load starts consuming.

$$
\text { pulse per } K W h=1.6
$$

$$
\text { elapsedKWh }=\left(\frac{1 \text { xpulseCount }}{\text { pulse per KWh } \times 1000}\right)
$$

c) Consumed Watt:

$$
\text { consumed watt }=\text { elapsedKWh } \times 1000
$$

d) Monthly cost bill:

$$
\text { cost per kwh }=M \$
$$

current bill amount $=$ elapsed $K W h \times$ cost per $k W h$ 
Figure 3 shows the flowchart of the software implementation.

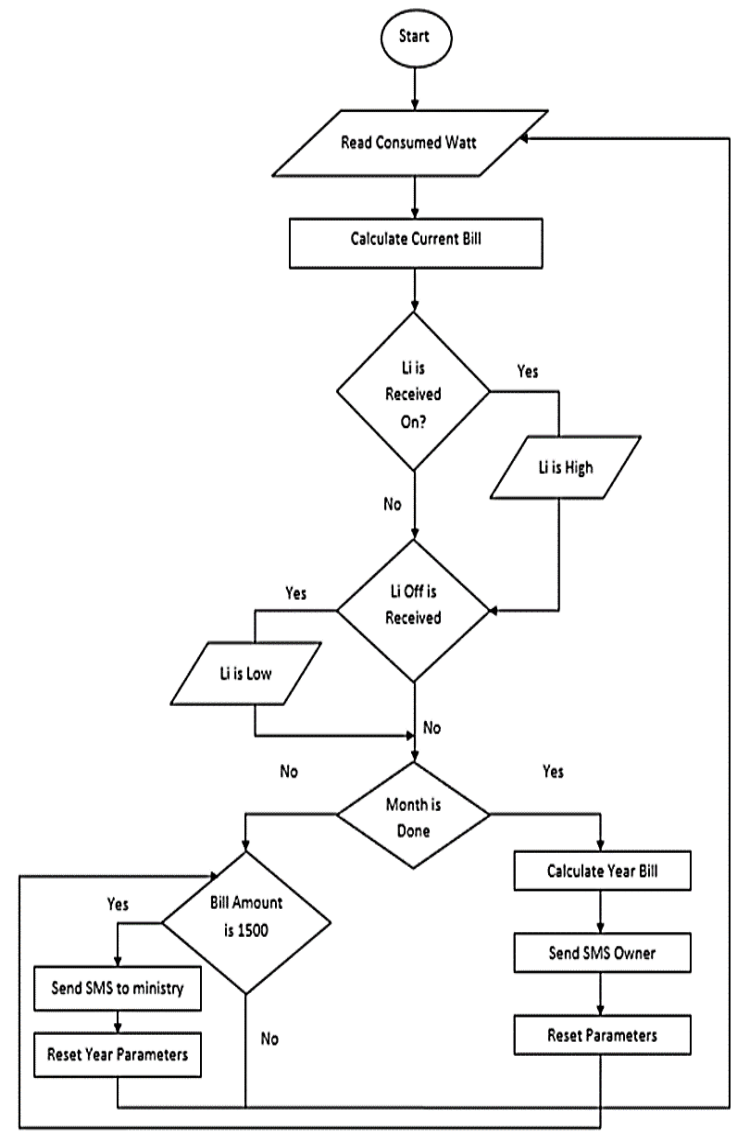

Fig. 3: Flowchart of software implemntation

\section{TESTING AND RESULTS}

In order to make sure that the system works as it was designed for, tests were performed and the results were compared with the theoretical values and the requirements of the functionality of our smart electricity meter

In fact, testing of the system was divided into many scenarios:

\section{A. The mobile network connection state:}

In order to check the functionality of sending and receiving messages, the GSM is checked for the presence of service. If the service is available the below line will show on the LED screen:

\section{Serial init oK GPRS init success}

Fig. 4: The service is available and high performance

In case of no service, the below line will show:

\section{GPRS init not successful}

Fig. 5: There is no service and poor performance

\section{B. No load scenario:}

All the light loads are off and there is no power. We only have GSM and Arduino that are fed from the battery. Naturally the reading of the energy consumption is 0 .

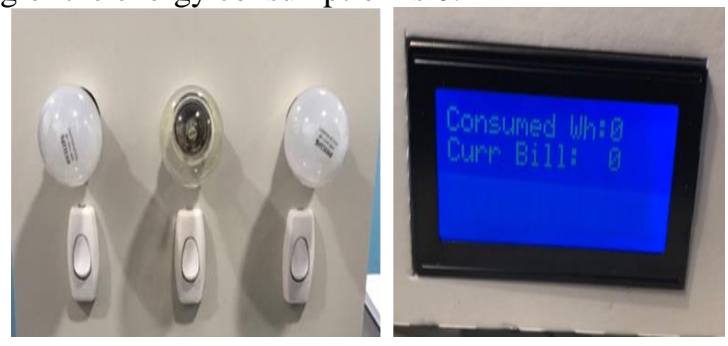

Fig. 6: No load state

C. Low consumption Loads
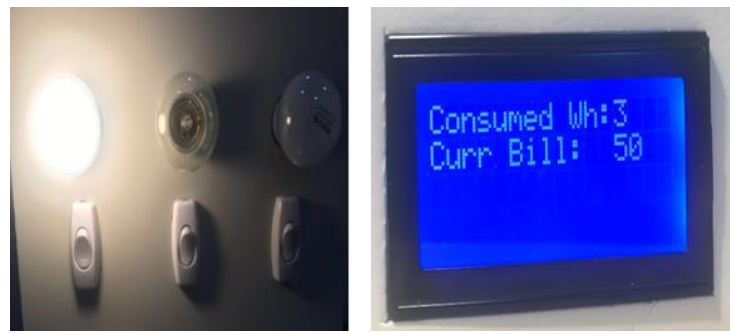

Fig. 7: Low consumption loads

\section{High consumption Loads}
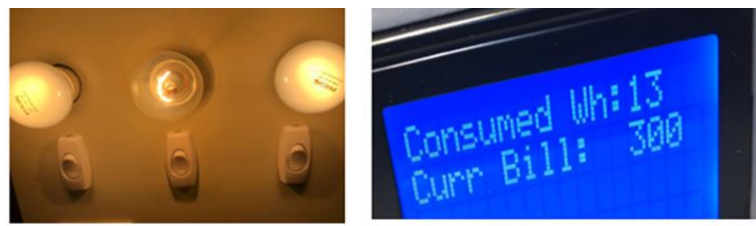

Dear Consumer, You reached the maximum monthly bill of 100 , please take an action

Fig. 8: Warning message sent when consumer reaches the maximum

\section{E. After one Month of consumption}

Your Monthly Bill in fils is:

475

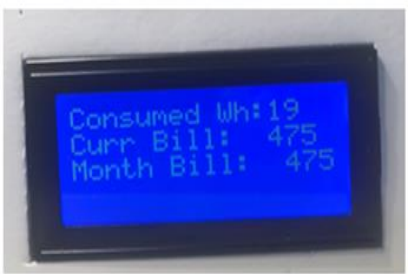

Fig. 9: Monthly Bill sent to cosumer 
F. Remote controlling of loads

\section{ON2}
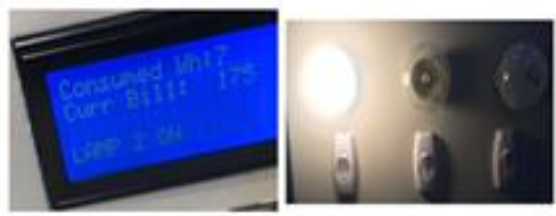

Fig. 10: Switching on the light through SMS

\section{OFF2}
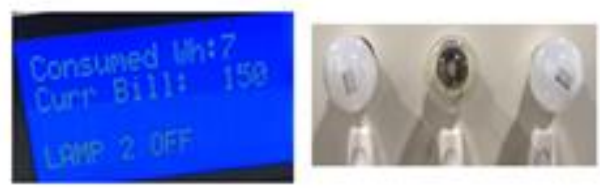

Fig. 11: Switching off the light through SMS

\section{G. The consumption reaching a maximum predetermined} value

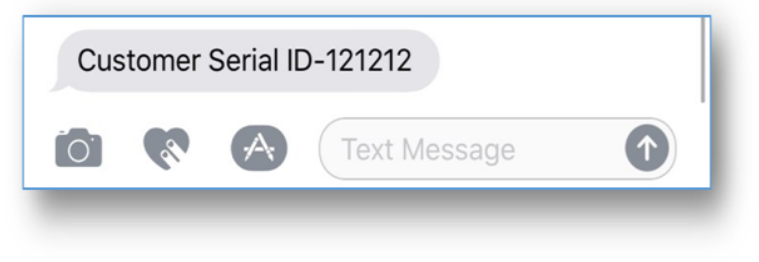

Fig. 12: The message sent to the electric utility

\section{CONCLUSION}

In this paper, a smart electricity metering system is designed and successfully implemented and tested. The system is composed of an energy meter, a GSM and microcontroller modules. The system could be added to any traditional existing energy meter to enhance its capabilities. The suggested system managed to introduce an automatic monthly billing system as well as full remote control of certain loads via SMS messages. The introduced metering system is characterized by being simple, reliable, inexpensive and easy to be implemented.

\section{REFERENCES}

[1] Jain, Abhinandan, Dilip Kumar, and Jyoti Kedia. "Design and Development of GSM Based Energy Meter." International Journal of Computer Applications 47.12 (2012): 41-45.

[2] Arduino - ArduinoBoardMega2560", Arduino.cc, 2017. https://www.arduino.cc/en/Main/ArduinoBoardMega2560.

[3] H. M. Zahid Iqbal, M. Waseem and Tahir Mahmood "Automatic Energy Meter Reading using Smart Energy Meter" Department of Electrical Engineering, University of Engineering \& Technology Taxila, Pakistan, 2013.

[4] Md. Mejbaul Haque, Md. Kamal Hossain, Md. Mortuza Ali and Md. Rafiqul Islam Sheikh "Microcontroller Based Single Phase Digital Prepaid Energy Meter for Improved Metering and Billing System", International Journal of Power Electronics and Drive System (IJPEDS).

[5] Abhinandan Jain, Dilip Kumar and Jyoti Kedia "Smart and Intelligent GSM based Automatic Meter Reading System", International Journal of Engineering Research \& Technology (IJERT), Vol. I Issue 3, pp. 1-6, May 2012.

[6] "WHAT IS ARDUINO?" Arduino - Home. [Online]. Available: https://www.arduino.cc

[7] Md. Masudur Rahman; Noor-E-Jannat; Mohd. Ohidul Islam; Md. Serazus Salakin "Arduino and GSM Based Smart Energy Meter for Advanced Metering and Billing System", Department of Electrical and Electronic Engineering, Pabna University of Science \& Technology, 2015.

[8] Qie Sun, Hailong Li, Zhanyu Ma, Chao Wang, Javier Campillo, Qi Zhang, Fredrik Wallin, and Jun Guo "A Comprehensive Review of Smart Energy Meters in Intelligent Energy Networks", IEEE INTERNET OF THINGS JOURNAL, VOL. 3, NO. 4, AUGUST 2016. 